\title{
A Waste Supply-Use Analysis of Australian Waste Flows
}

\section{Christian John Reynolds • Julia Piantadosi • John Boland}

Received: 18 March 2014 / Revised: 28 August 2014 / Accepted: 19 October 2014 /

Published online: 06 November 2014

(C) 2014 Reynolds et al.; licensee Springer. This is an Open Access article distributed under the terms of the Creative Commons Attribution License (http://creativecommons.org/licenses/by/4.0), which permits unrestricted use, distribution, and reproduction in any medium, provided the original work is properly credited.

\begin{abstract}
In this paper we apply the Lenzen and Reynolds (2014) Waste Supply Use Table extension of Nakamura and Kondo's (2002a) Waste Input-Output (WIO) framework to the 2008 Australian economy. This is the first application of any WIOstyle method to Australia as a nation. We find that the Services sector has the largest direct and indirect waste generation for an intermediate sector. This is followed by the Forestry sector, for direct waste generation, and the Transport sector for direct and indirect waste generation effects.

In terms of waste treatment methods, landfill generates the smallest direct and indirect waste tonnages, but it also provides the least amount of economic activity per tonne treated, producing \$US2.53 in total of economic production per tonne treated.
\end{abstract}

Keywords Food waste - Commercial and industrial waste $\cdot$ Municipal solid waste Australia input-output

JEL Classification Q53 - Q56 - Q57

\section{Introduction}

Waste Input-Output (WIO) analysis can provide much needed information regarding the economic impact of waste generated by sectors of the economy. A WIO (or

Electronic supplementary material The online version of this article (doi:10.1186/s40008-014-0005-0) contains supplementary material.

C.J. Reynolds $(\varangle) \cdot$ J. Piantadosi · J. Boland

Centre for Industrial and Applied Mathematics and the Barbara Hardy Institute, University of South Australia, Mawson Lakes Boulevard, Mawson Lakes, SA 5095, Australia

e-mail: christian.reynolds@unisa.edu.au

C.J. Reynolds

Integrated Sustainability Analysis, University of Sydney, Sydney, Australia 
Waste Supply Use Table (WSUT)) analysis provides the means to devise interventions and policy with a sectoral focus (Nakamura and Kondo 2002a; Kagawa 2005; Kagawa et al. 2007; Tsukui 2007; Lin 2009; Tsukui and Nakamura 2010; Matsubae et al. 2011; Tsukui et al. 2011, 2012). Yet there has never been a WIO of Australia constructed, primarily because the level of waste data required for a WIO have been too high (though previously there has been some attempted IO analysis of waste in Australia (Reynolds and Boland 2011, 2013a, 2013b; Reynolds et al. 2011). However, thanks to the high resolution waste data set of Australia discussed in Lenzen and Reynolds (2014), WIO analysis for Australia is now a reality.

In this paper we apply Lenzen and Reynolds (2014) extension of Nakamura and Kondo's WIO framework, first published in English as (Nakamura 1999), and later (Nakamura and Kondo 2002a, 2002b, 2002c, 2006, 2008, 2009; Nakamura et al. 2007; Nakamura 2010) to the Australian economy. It is worth noting again that this is the first application of any WIO-style method to Australia as a nation.

In Sect. 2 we discuss the methodology, data sources and procedures followed to create an Australian WSUT. In Sect. 3 we present the results of a practical application of the WSUT methodology to Australia, and discuss these results in Sect. 4. Section 5 provides concluding remarks. In Appendix A (Additional files 1-3) we list the direct and indirect waste multipliers for 343 intermediate sectors and ten waste treatment sectors in the Australian economy as of 2008, as well as the disaggregated tonnages of industrial solid waste (ISW) and municipal solid waste (MSW). In Appendix B (Additional file 4) we provide analysis of the largest direct and indirect waste multipliers for 14 waste types. In Appendix C (Additional file 5) we provide unaltered versions of the aggregated seven sector Coefficients and Leontief matrices (Tables 2 and 3) for comparison, and a concordance matrix between the 7 and 343 sector versions of the WSUT. For completeness we also include the simplified Transactions matrix and the Gross output vector used for calculations.

\section{Methodology}

\subsection{WSUT Notation}

In this paper we will use the notation described in Lenzen and Reynolds (2014). The WSUT in balanced form is written as

$$
\left(\begin{array}{ccc}
\mathbf{T}_{11} & \mathbf{T}_{12} & \mathbf{0} \\
\mathbf{0} & \mathbf{0} & \mathbf{W}_{23} \\
\mathbf{W}_{31} & \mathbf{W}_{32} & \mathbf{0}
\end{array}\right)\left(\begin{array}{l}
\mathbf{1}_{1} \\
\mathbf{1}_{2} \\
\mathbf{1}_{3}
\end{array}\right)+\left(\begin{array}{c}
\mathbf{f} \\
\mathbf{0} \\
\mathbf{W}_{F}
\end{array}\right) \mathbf{1}_{F}=\left(\begin{array}{l}
\mathbf{x}_{1} \\
\mathbf{x}_{2} \\
\mathbf{x}_{3}
\end{array}\right)
$$

where $\mathbf{T}_{11} \in \mathbf{R}^{N_{1} \times N_{1}}$ represents an intermediate demand matrix for $N_{1}$ goods and service-producing sectors, $\mathbf{f} \in \mathbb{R}^{N_{1} \times N_{F}}$ a final demand matrix for $N_{F}$ final demand categories, and $\mathbf{x}_{1} \in \mathbb{R}^{N_{1} \times 1}$ a gross output vector for $N_{1}$ goods and serviceproducing sectors, respectively. Waste generation is categorised per intermediate sector as $\mathbf{W}_{31} \in \mathbb{R}^{N_{3} \times N_{1}}$, and final demand as $\mathbf{W}_{F} \in \mathbb{R}^{N_{3} \times N_{F}}$, distinguishing $N_{3}$ waste types in the economy. The monetary inputs $\mathbf{T}_{12} \in \mathbb{R}^{N_{1} \times N_{2}}$ into $N_{2}$ waste treatment 
sectors (applying $N_{2}$ treatment methods) are distinguished from the monetary inputs $\mathbf{T}_{11}$ into other intermediate sectors. The waste produced by $N_{2}$ waste treatment sectors is represented by $\mathbf{W}_{32} \in \mathbb{R}^{N_{3} \times N_{2}}$ represent and the waste treated by the $N_{2}$ waste treatment methods is contained in $\mathbf{W}_{23} \in \mathbb{R}^{N_{2} \times N_{3}}$. The vectors $\mathbf{x}_{3} \in \mathbb{R}^{N_{3} \times 1}$ and $\mathbf{x}_{2} \in \mathbb{R}^{N_{2} \times 1}$ are the total output of $N_{3}$ waste types and $N_{2}$ waste treatment methods for the economy, respectively. $\mathbf{1}_{1}, \mathbf{1}_{2}, \mathbf{1}_{3}$, and $\mathbf{1}_{F}$ are column vectors of ones with appropriate dimensions.

We can express Eq. (1) in coefficient form, given by

$$
\left(\begin{array}{ccc}
\mathbf{A}_{11} & \mathbf{A}_{12} & \mathbf{0} \\
\mathbf{0} & \mathbf{0} & \mathbf{S}_{23} \\
\mathbf{G}_{31} & \mathbf{G}_{32} & \mathbf{0}
\end{array}\right)\left(\begin{array}{l}
\mathbf{x}_{1} \\
\mathbf{x}_{2} \\
\mathbf{x}_{3}
\end{array}\right)+\left(\begin{array}{c}
\mathbf{f} \\
\mathbf{0} \\
\mathbf{W}_{F}
\end{array}\right) \mathbf{1}_{F}=\left(\begin{array}{l}
\mathbf{x}_{1} \\
\mathbf{x}_{2} \\
\mathbf{x}_{3}
\end{array}\right)
$$

where we define input coefficients matrices $\mathbf{A}_{11}=\mathbf{T}_{11} \hat{\mathbf{x}}_{1}^{-1}(\$ / \$), \mathbf{A}_{12}=\mathbf{T}_{12} \hat{\mathbf{x}}_{2}^{-1}(\$ / \mathrm{t})$, $\mathbf{G}_{31}=\mathbf{W}_{31} \hat{\mathbf{x}}_{1}^{-1}(\mathrm{t} / \$)$, and $\mathbf{G}_{32}=\mathbf{W}_{32} \hat{\mathbf{x}}_{2}^{-1}(\mathrm{t} / \mathrm{t})$, where the "hat" over a vector $\mathbf{x}$ denotes a diagonal matrix with the elements of the vector along the main diagonal. For instance, if $\mathbf{x}=\left[\begin{array}{l}x_{1} \\ x_{2}\end{array}\right]$ then $\hat{\mathbf{x}}=\left[\begin{array}{cc}x_{1} & 0 \\ 0 & x_{2}\end{array}\right]$. The matrix $\mathbf{S}_{23} \in \mathbf{R}^{N_{2} \times N_{3}}$ is an $N_{2} \times N_{3}$ version of Nakamura and Kondo's (2009) allocation matrix (Nakamura and Kondo 2002a). The elements of $S_{23}(i, j)$ refer to the share of waste type $j$ that is treated by treatment method $i$, and are normalised according to $\sum_{j} S_{23}(i, j)=1$.

The Leontief inverse of the WSUT is finally formulated as follows:

$$
\left(\begin{array}{l}
\mathbf{x}_{1} \\
\mathbf{x}_{2} \\
\mathbf{x}_{3}
\end{array}\right)=\left(\begin{array}{ccc}
\mathbf{I}-\mathbf{A}_{11} & -\mathbf{A}_{12} & \mathbf{0} \\
\mathbf{0} & \mathbf{I} & -\mathbf{S}_{23} \\
-\mathbf{G}_{31} & -\mathbf{G}_{32} & \mathbf{I}
\end{array}\right)^{-1}\left(\begin{array}{c}
\mathbf{f} \\
\mathbf{0} \\
\mathbf{W}_{F}
\end{array}\right) \mathbf{1}_{F} .
$$

\subsection{Data Sources and Processing}

In Lenzen and Reynolds (2014) a national Australian WSUT for 2008 was provided as a technical example. We now further describe the data sources, processing and compilation methods used to create this WSUT.

The Australian IO table was sourced from the Eora database in US dollars (Lenzen et al. 2011, 2012a, 2012b, 2013), to provide the WSUT block $\mathbf{T}_{11}$, distinguishing $N_{1}=343$ industry sectors. Waste data were estimated (as discussed in Lenzen and Reynolds 2014 and Reynolds 2013), with only formal disposal accounted for. This waste estimation methodology is discussed in abridged form below.

The Australian waste treatment sector is quite small employing $~ 3,300$ persons, ( $0.3 \%$ of total Australian labour) and generating 9 billion AU\$ gross output in 20092010. This can be explained by the majority of waste being sent to landfill, with much of the recycled/recovered material being sent overseas for reprocessing (Australian Bureau of Statistics 2013a). In addition to being small in size, the Australian waste (and recycling) treatment sector is not well documented, thus to create this WSUT we disaggregated the recycling parts from Eora sector \#344 'Sanitary and garbage disposal' into the block $\mathbf{T}_{12}$, yielding $N_{2}=10$ separate treatment sectors, using data/sector labels on recycling from Department of Sustainability, Environment, 
Water, Population and Communities (DSEWPaC) (DSEWPaC 2012) and Hyder Consulting (Hyder Consulting 2012). ${ }^{1}$ Waste data for WSUT block $\mathbf{W}_{31}$, distinguishing Municipal Solid Waste (MSW), Commercial and Industrial (C\&I), and Construction and Demolition (C\&D) origins were sourced from the Australian Bureau of Statistics (Australian Bureau of Statistics 2008, 2009, 2010, 2011, 2013b), as well as Hyder Consulting (Hyder Consulting 2012), DSEWPaC (Department of Sustainability, Environment, Water, Population and Communities 2012; Environment Protection and Heritage Council and the Department of Environment, Water, Heritage and the Arts 2010), and Inside Waste (WCS Market Intelligence 2008; Waste Management \& Environment Media Pty Ltd 2011). Data on recycling (WSUT block $\mathbf{W}_{32}$ ) were sourced from DSEWPaC (DSEWPaC 2012) and Hyder Consulting (Hyder Consulting 2012). $\mathbf{W}_{F}$ was estimated using MSW data $(2008,2012)$. This step is an assumption for simplicity, as MSW is produced by households and households are the major contributor to final demand. Finally, $\mathbf{S}_{23}$ and $\mathbf{W}_{23}$ were populated using data from Wright Corporate Strategy Pty Ltd and Rawtec Pty Ltd (Wright Corporate Strategy Pty Ltd and Rawtec Pty Ltd 2010) and Hyder Consulting (Hyder Consulting 2012). In our example we distinguish $N_{3}=14$ waste types. ${ }^{2}$ Where data were aggregated across the $N_{1}=344$ industry sectors, we applied a prorating procedure using sectoral economic output (x, gross output) as a proxy (see Lenzen et al. 2012a, 2012b for more details).

To disaggregate the waste generation and treatment data for $\mathbf{W}_{31}$ we utilised a binary concordance matrix that uniquely allocates $C \& I$ and $C \& D$ waste streams to the 344 sectors of the Eora database's Australian IOT. C\&D waste producing sectors were understood to be numbered 68, 170, 218, 232, 243-249, 253255, and 257. Fourteen waste types (Organics (Food, Green); Timber; Textiles And Clothing; Paper, Printing, And Cardboard; Plastics; Rubber; Glass; Plaster Board; Cement And Construction; Metals (Ferrous, Non-Ferrous); Electronic Waste; and Other), were mapped across the intermediate sectors using the average from three proxy vectors: total sectoral gross output per sector, employment per sector, and the amount of inputs of production per intermediate sector (Reynolds 2013; Lenzen and Reynolds 2014). This method assumes that each sector produces waste relative to its economic size and employment capacity: i.e. we distributed the total amount of waste among the waste treatment methods with the larger the economic size and employment level, the greater the volume of waste was assumed to have been treated. No assumptions were made regarding the relative technological efficiency of waste generation between sectors.

The composition of waste generated by each sector is assumed to be unique, and so was estimated by applying industry $\rightarrow$ product $\rightarrow$ waste concordance matrices to normalised versions of the matrices $\mathbf{A}_{11}$ (the direct inputs between the intermediate sectors of the economy), and $\mathbf{A}_{12}$ (the direct inputs between the intermediate sector of the economy, and the waste treatment sectors). These concorded $\mathbf{A}$ matrices

\footnotetext{
${ }^{1}$ Landfill (Lf), and recycling of glass (Gl R), paper and cardboard (Ppr R), plastics (Pla R), metals (Me), organics treatment and commercial composting (Or C), construction \& demolition (Cn R), e-waste (EW R), leather and textiles (Le R), and tires and other rubber (Ru R).

${ }^{2}$ Food waste (Food), green waste (Gdn), timber (Tim), textiles and clothing (Txt), paper, printing and cardboard (Ppr), plastics (Pla), rubber $(\mathrm{Ru})$, glass $(\mathrm{Gl})$, plaster board $(\mathrm{Pb})$, cement and construction $(\mathrm{Cn})$, ferrous metals (M F), non-ferrous metal (MNF), electronic waste (EW), and other (Oth).
} 
were multiplied by total waste produced per sector to replicate the phenomenon of each product/industry having different waste types associated with its consumption and production. For example, the sectors of Forestry (sector number 35), Softwoods (36), and Hardwoods (37) are all sectors associated with Timber products, which is in turn associated with Timber waste. Each sector that has a part of its direct requirements (coefficient multiplier) attributed to Forestry (35), Softwoods (36), etc. will be assumed to produce a proportional amount of timber waste relative to the amount of timber products used in its production processes. For full discussion of this methodology please refer to Reynolds (2013).

To summarise, the resulting Australian WSUT model has $N_{1}=343, N_{2}=10$, and $N_{3}=14$. Note that $N_{1}$ has one sector less than the equivalent Eora table, as this sector has been disaggregated to become $N_{2}$.

\section{Results}

Table 1 displays a simplified WSUT constructed for Australia for 2008. For the sake of readability it presents the waste flows of Australia as a 31 by 31 table (with seven aggregated intermediate industry sectors, 10 treatment sectors, and 14 waste types). A concordance matrix to convert from the 343 to the seven sector model is supplied in Appendix C. Aggregation of sectors was based on a condensed version of the Australian and New Zealand Standard Industrial Classification (Australian Bureau of Statistics 2006). Note that this is a simplified table with import, exports, and some final demand categories excluded from this table (and thus from Table 1's gross output values).

Waste volumes are reported in physical units of one million tonnes and monetary units of one billion US dollars. US dollars were used to keep consistency with the Eora tables, which use USD as a base currency.

The $\mathbf{W}_{31}$ section of Table 1 presents a breakdown of waste type generated by each intermediate sector of the Australian economy. Waste generation by treatment sector is listed in the $\mathbf{W}_{32}$ section. The $\mathbf{W}_{23}$ section provides the waste volumes processed by each treatment type. The $\mathbf{W}_{F}$ section provides the Australian MSW data. The $\mathbf{x}_{2}$ and $\mathbf{x}_{3}$ sections give the total tonnages of waste sorted by treatment type or waste type.

Tables 2 and 3 display the aggregated direct and total waste generation multipliers created from the full Australian WSUT that is presented as simplified in Table 1. Monetary gross output values were sourced directly from the EORA database and so contain full imports and export data, these values can be found in Appendix C. Caution should be used when reading Tables 2 and 3, as there are multiple scales presented on the one table (millions of dollars per millions of dollars; dollars per tonne; kilograms per tonne and tonnes per millions of dollars), Table 2 uses an additional scale for the coefficients of $\mathbf{S}_{23}$-tonnes per tonnes-in order to illustrate the integration of the $\mathbf{S}_{23}$ matrix into the WSUT.

Corresponding with Eqs. (2) and (3), the $\mathbf{G}_{31}$ and $\mathbf{G}_{32}$ sections of the Tables 2 and 3 show the waste generation coefficients and multipliers. Table 2 presents the direct waste generation multipliers: the waste that was produced directly in the associated sector due to economic activity within that sector. Table 3 presents the total 


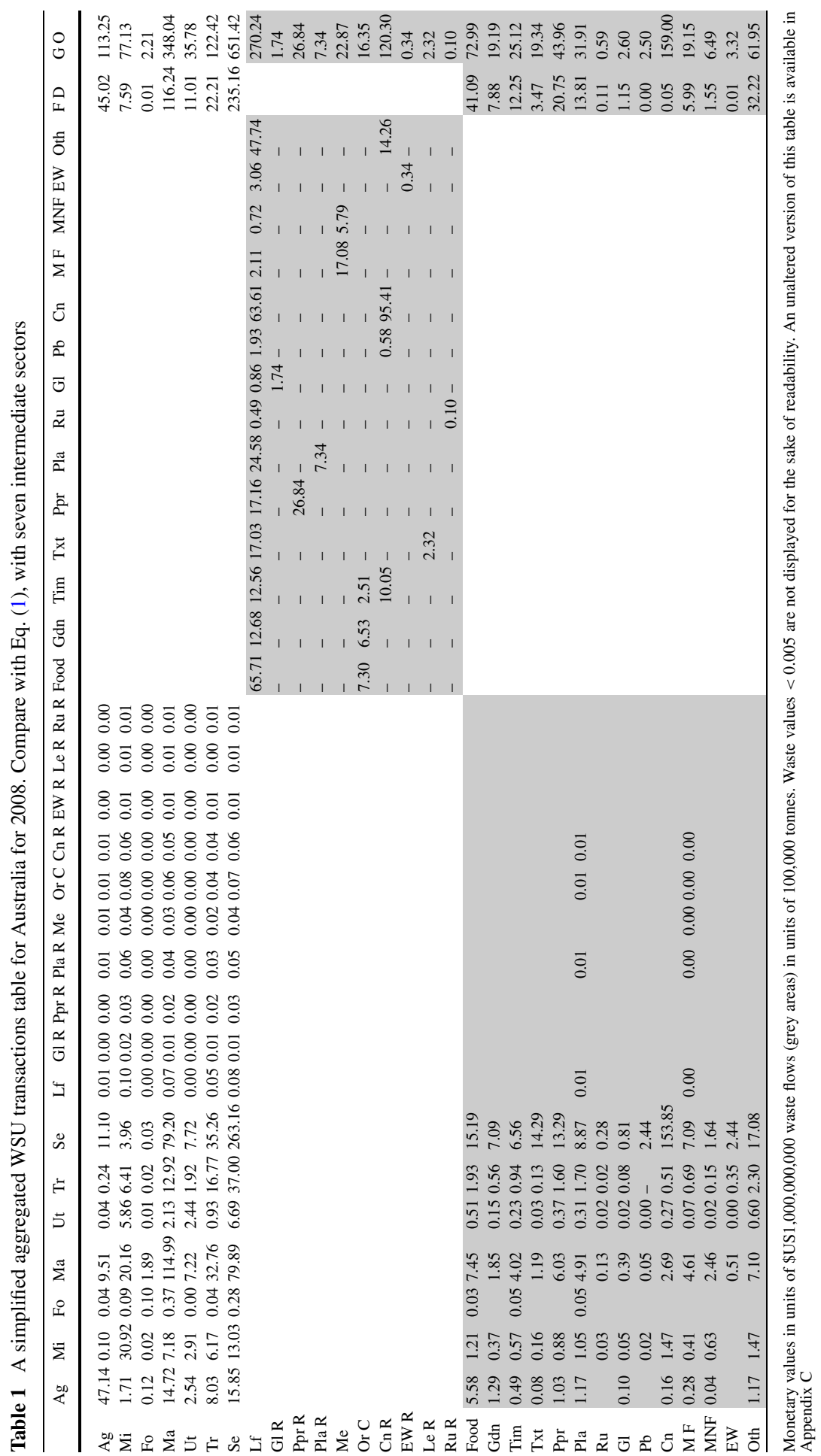




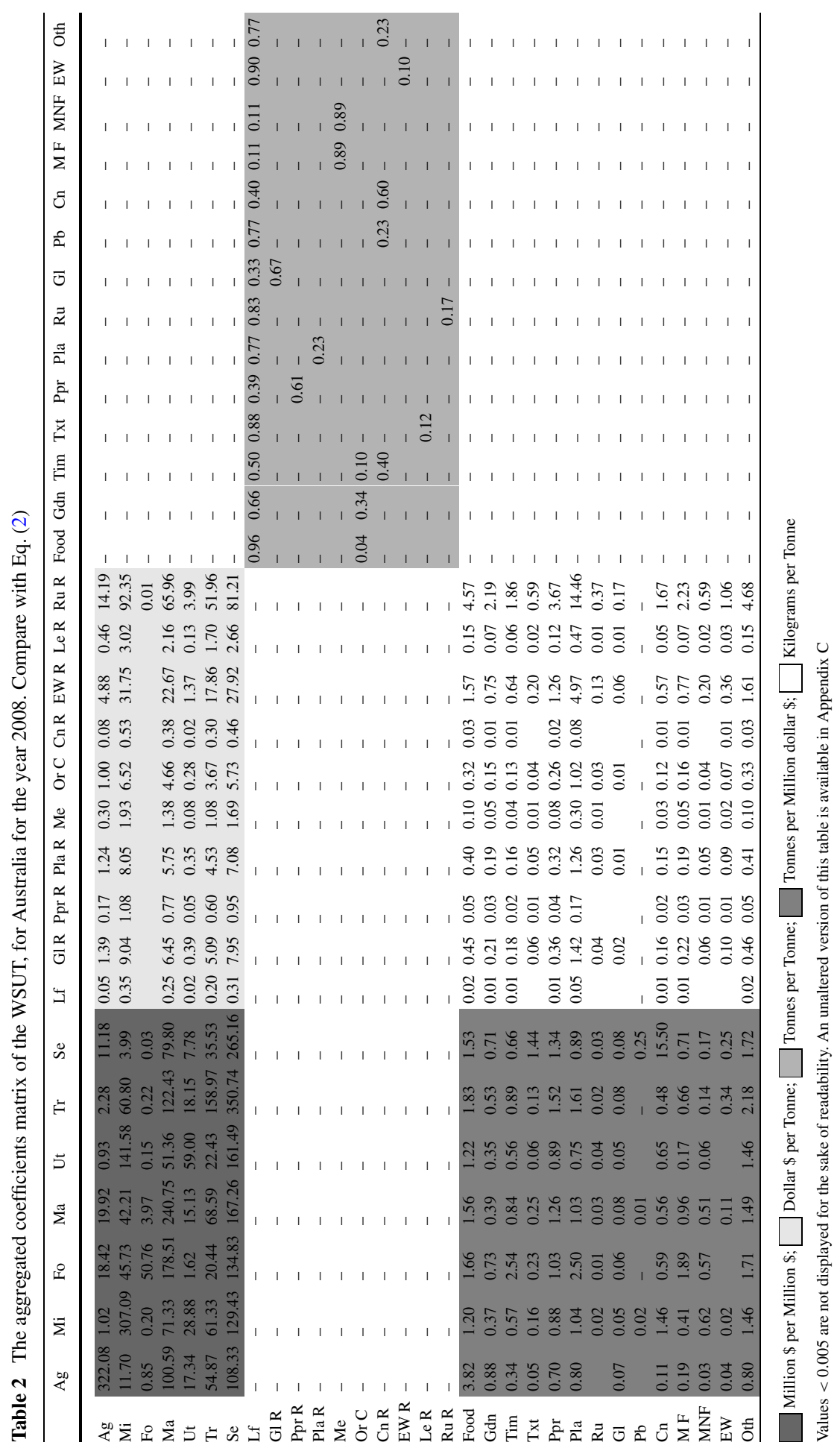




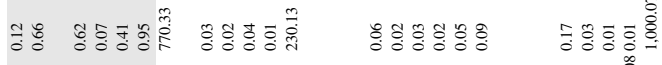
음

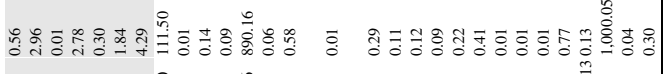

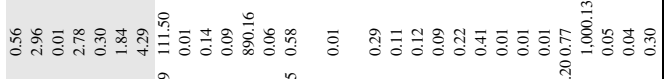

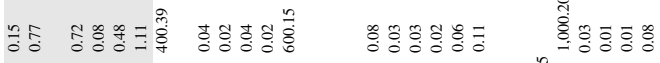

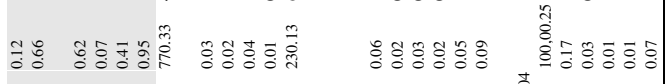

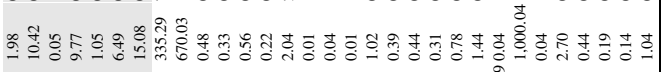

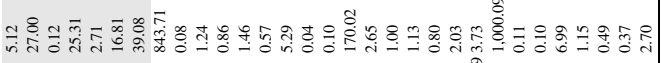

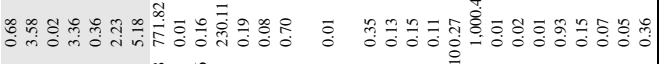

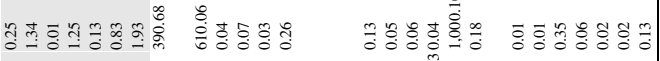

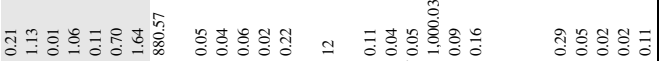

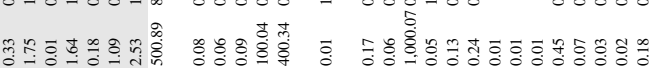

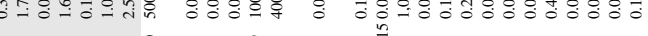

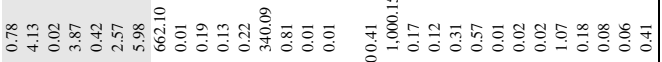

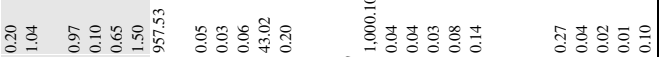

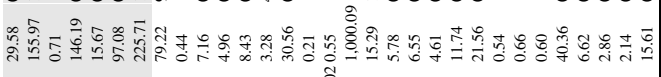

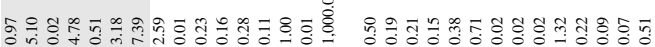
10

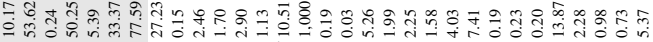

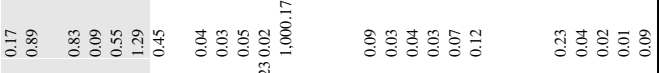

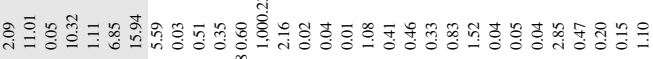

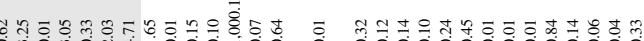

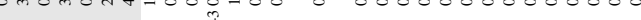

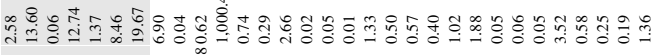

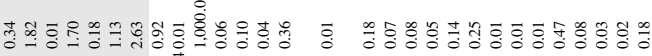

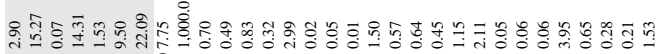
₹

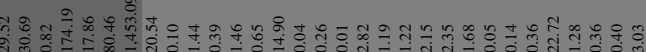
車 罂

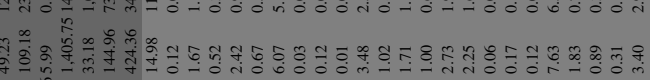

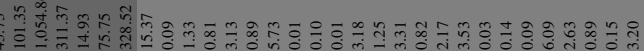

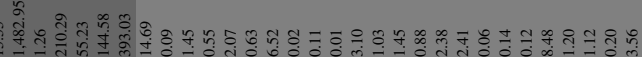

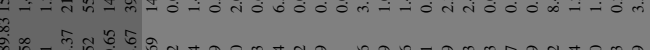


Table 4 Total waste generation effects (tonnes per \$US1,000,000 of output) listed as direct, indirect and total effects for the intermediate sectors

\begin{tabular}{lcll}
\hline Industry & Direct effects & Indirect effects & Total effects \\
\hline Agriculture & 7.83 & 17.88 & 25.71 \\
Mining & 8.28 & 17.84 & 26.13 \\
Forestry & 13.52 & 13.95 & 27.47 \\
Manufacturing & 9.08 & 17.51 & 26.59 \\
Utilities & 6.27 & 13.48 & 19.75 \\
Transport & 10.39 & 24.84 & 35.22 \\
Services & 25.28 & 14.49 & 39.78 \\
\hline
\end{tabular}

Table 5 Total waste generation effects (kilograms per tonne) listed as direct, indirect and total effects for the waste treatment sectors

\begin{tabular}{lccr}
\hline Industry & Direct effects & Indirect effects & Total effects \\
\hline Landfill & 14.38 & 36.52 & 50.90 \\
Glass (recycling) & 372.94 & 947.39 & $1,320.34$ \\
Paper and cardboard (recycling) & 44.36 & 112.68 & 157.04 \\
Plastics (recycling) & 332.15 & 843.75 & $1,175.90$ \\
Metal (recycling) & 79.51 & 201.98 & 281.49 \\
Organics composting & 269.08 & 683.54 & 952.62 \\
Construction \& demolition (recycling) & 21.71 & 55.15 & 76.86 \\
Electronic waste (recycling) & $1,309.94$ & $3,327.68$ & $4,637.63$ \\
Leather \& textiles (recycling) & 124.70 & 316.76 & 441.46 \\
Tyres \& other rubber (recycling) & $3,810.67$ & $9,680.18$ & $13,490.86$ \\
\hline
\end{tabular}

waste generation multipliers determined through the Leontief inverse (Eq. (3)): the waste produced in an individual sector, plus the waste produced throughout the supply chain that enables this sector's production.

Table 4 and 5 presents the direct, indirect and total waste generation, in tonnes per million dollars and tonnes per tonne for the intermediate industry sectors and the expanded waste treatment sectors. Table 6 presents the column sums of $\mathbf{A}_{12}$ from Tables 2 and 3, this can be interpreted as the total economic stimulus per tonne treated (dollars per tonne) listed as direct and total effects for the waste treatment sectors. Direct waste generation is the waste generated by an industry's own on-site production processes. Indirect waste generation is the volume of waste generated throughout the supply chain as a result of the production processes of all industries in that supply chain underpinning the production of this final product. Total waste generation is the sum of the direct and indirect waste generation. A comprehensive list of the direct and total waste generation multipliers for all 343 intermediate sectors and ten waste treatment sectors can be found in Appendix A.

From Table 4 we observe that the Services sector has the largest direct and total waste generation for an intermediate sector. This is followed by the Forestry sector, for direct waste generation, and the Transport sector for total waste generation effects. 
Table 6 Economic stimulus per tonne treated (US dollars per tonne) listed as direct and indirect effects for the waste treatment sectors (the column sums of $\mathbf{T}_{12}$ sections from Tables 2 and 3)

\begin{tabular}{lcc}
\hline Industry & $\begin{array}{l}\text { Direct effects } \\
\text { (column sums in } \mathbf{T}_{12} \\
\text { section from Table 2) }\end{array}$ & $\begin{array}{c}\text { Direct and indirect effects } \\
\text { (column sums in } \mathbf{T}_{12} \\
\text { section from Table 3) }\end{array}$ \\
\hline Landfill & 1.17 & 2.53 \\
Glass (recycling) & 30.31 & 65.66 \\
Paper and cardboard (recycling) & 3.60 & 7.81 \\
Plastics (recycling) & 26.99 & 58.48 \\
Metal (recycling) & 6.46 & 14.00 \\
Organics composting & 21.87 & 47.37 \\
Construction \& demolition (recycling) & 1.76 & 3.82 \\
Electronic waste (recycling) & 106.45 & 230.64 \\
Leather \& textiles (recycling) & 10.13 & 21.95 \\
Tyres \& other rubber (recycling) & 309.67 & 670.91 \\
\hline
\end{tabular}

This could indicate that although the Transport and Service sector can be thought of as tertiary industries that produce large volumes of waste, they are also interlinked with the rest of the economy to a high degree as shown by their high indirect and total effects. Meanwhile, Forestry can be understood to be a sector that, though producing a relatively large volume of waste directly, has smaller indirect waste generation. The relatively smaller indirect waste generation of Forestry can be related to the Forestry sectors supply chains: as they feature less waste generation intensive industries.

The high indirect waste generation found in Agriculture, Manufacturing, and Mining is significant, as industry and government reports show that current waste reduction strategies focus on secondary and tertiary sectors rather than on primary industries. The importance of waste reduction strategies for primary activities such as mining and agriculture needs to be re-examined in light of these results (Department of Environment and Climate Change NSW 2007; Zero Waste South Australia 2007; ACT NOWaste 2008; Environment Division, Department of Environment, Parks, Heritage and the Arts 2009).

An examination at 343 sector detail, indicates some similar result to the seven sector model with the construction and other Service sectors being dominant throughout the 30 largest direct waste generating sectors. An exception to this is the 19th largest direct waste generating sector: Sector \#34 'Other forest products' (Forestry), while spot 31 of the largest direct waste multipliers is the Forestry sector (\#35). This echoes the results of the seven sector model.

The sectors with the largest total waste multipliers were again predominantly construction (service) sectors followed by other Service sectors. However, in deviation from the seven sector model, the first transport sector is found at the 34th rank: Sector \#278 'Overseas communication services', with the remaining the transport sectors ranked much lower. This implies that the above result-that the transport sector has a large total waste multiplier-could be due to aggregation effects rather than the individual sectors having large total waste multipliers. This gives warning to those who would take results from aggregation without examining the detailed datasets. 
Please refer to Appendices A and B for data and detailed analysis of the 343 waste generating sectors.

\subsection{Treatment Analysis}

The $\mathbf{S}_{23}$ section of Table 2 indicates landfill (Lf) as the dominant treatment method in terms of tonnes treated. The results in Table 5 indicate that landfill generates smaller direct and total waste tonnages when compared to the various recycling treatments. Electronic waste, Tyres and other rubber, and Glass recycling are the three most 'inefficient' waste treatment sectors in terms of both direct and total waste generation effects; as in treating a tonne of waste they produce the largest volume of waste products. Notably the volume of total waste generated is larger than the volume of waste originally treated (Rubber 13:1, Electronic waste 4:1, Glass 1.3:1). However, the composition of this 'new' waste is mixed rather than singular. Technically, recycling via these inefficient methods could be understood to be transforming (at a macroeconomic level) a single type of waste into greater tonnages of other types of waste rather than actual 'treatment'.

In current Australian circumstance (i.e. overall reliance on landfill as a treatment method), this finding also implies that as greater volumes of these wastes are 'inefficiently' recycled, a greater volume of waste overall will be sent to landfill. This situation will begin to change if these treatment methods become more efficient, and over $50 \%$ of Australia's waste is recycled.

This result shows that the technologically and labour intensive treatment methods produce a greater volume of waste per tonne treated than the less technologically complex and labour intensive treatment method of landfill. This finding confirms what was already intuitively suspected: the activity of burying waste in the ground inherently produces less waste per tonne than recycling the waste (via relatively labour and monetarily intensive methods). However, it is worth being reminded that once landfilled, the waste material can then no longer be used as an input of production.

Landfill provides the least amount of economic activity per tonne treated. As indicated in Table 6, for every tonne of waste disposed of via landfill stimulates \$US1.17 direct, or \$US2.53 in total of economic activity. This is low compared to the more technologically and labour intensive treatment methods such as rubber recycling (\$US310 in direct effects, and \$US671 in direct and indirect effects of economic production per tonne treated), or electronic waste recycling (\$US106 for direct effects, and \$US230 in direct and indirect effects of economic production per tonne treated). However, at present, with landfill the dominant treatment method, each tonne of rubber or electronic waste treated produces economic production worth only \$US116 or \$US25 (Table 7). This result indicates that recycling provides a larger economic production than landfill per tonne of waste treated, and that there is room to improve the economic stimulus associated with waste treatment by diverting waste from landfill to recycling.

We have used the term 'economic stimulus' to indicate the amount of money associated with an additional tonne of waste being treated in each manner. This monetary value could likewise be understood to be related to labour, monetary and material flows). This means that each per tonne economic stimulus could likewise be described 
Table 7 The direct and indirect economic stimulus per tonnes of waste type (US dollars per tonne)

\begin{tabular}{lc}
\hline Industry & $\begin{array}{c}\text { Current economic } \\
\text { stimulus/cost }\end{array}$ \\
\hline Food organics & 4.46 \\
Garden organics & 17.77 \\
Timber (construction/organics) & 7.53 \\
Textiles and clothing & 4.86 \\
Paper, printing, cardboard & 5.75 \\
Plastics & 15.40 \\
Rubber & 116.13 \\
Glass & 44.82 \\
Plaster board & 2.83 \\
Cement and construction & 3.31 \\
Metal ferrous & 12.74 \\
Metal non-ferrous & 12.74 \\
Electronic waste & 25.34 \\
Other & 2.83 \\
\hline
\end{tabular}

as a cost of diversion. However, these 'costs' allow the selection of treatment methods that produce usable products or material inputs (recycling) rather than simply burying waste in the ground. This - to us - is a positive, that along with greater employment and consumption implies a stimulus. As the WSUT is static, our analysis has not modelled the substitution price effects that would occur as more recycled material is available as inputs. This is an avenue for further research.

It should also be noted that the primary function of waste treatment is to treat waste efficiently — not to provide an economic stimulus. Thus, leaving aside a discussion of disposable consumption culture inducing greater levels economic production (Thompson 1979; O'Brien 1999), we understand there to be more efficient methods of economic stimulus than changing treatment methods.

\section{Waste Analysis}

In Table 1 it can be observed that construction waste is the main contributing waste type $(61 \%)$, to the aggregated Services sector. Examining the disaggregated data from Table A3, Appendix A, it can be observed that within the aggregated Services sector, the ten sectors that have the largest direct and total multipliers-Residential building repair and maintenance (\#243), Residential building construction (\#244), Nonresidential building construction (\#245), Non-residential building repair and maintenance (\#246), Non-building construction (\#248), Non-building repair (\#249), Industrial machinery repairs (\#253), Business machines and equipment repairing and services (\#254), Wholesale repair and servicing (\#255), and Retail repair and service (\#257) — all principally produce construction waste. Other waste (8\%) and Food waste $(7 \%)$ are the second and third largest type of waste to contribute to the aggregated Service sectors waste footprint. The disparity between Construction waste and 
all other waste types within the aggregated service sector is due to the C\&D waste stream (which is exclusively these sectors) consisting of primarily construction-based waste.

Primary industries have a more varied waste composition, even though organic and construction wastes are again the prevalent waste types in the aggregated Mining and Agricultural sectors. Surprising results include Phosphate rock (\#72), having a high direct and total organic waste component; and Eggs (\#14), having a large indirect construction waste footprint due to its inputs (and thus waste) from the Non-building construction (\#248) sector.

For many of the results the sectors with the largest direct and total waste multipliers are sector Phosphate Rock (\#72) and sector Natural Rubber (\#28). This is because both these sectors have very large multipliers-in many cases three times larger than the other largest sectors in that waste category. The reason for Phosphate Rock and Natural Rubber having large multipliers is that they are the two smallest waste generating sectors of the Australian economy for 2008, and so produce a very small amount of waste. They are also small economic sectors and so relative to their economic activity they produce a very large amount of waste. This illustrates that just because a sector has a high multiplier it does not equate to the importance of that sector in terms of economic influence or that it currently produces a high tonnage of waste.

In Appendix B we discuss the largest direct and total waste multipliers for each of the 14 waste types. Please refer to Appendix A for a full list of all sectors and waste types direct and total multipliers.

\section{Conclusion}

In this paper we have applied the WSUT method proposed by Lenzen and Reynolds (2014) to the Australian economy. To our knowledge this is the first application of the waste IO methodology to Australia - a very exciting outcome. The resulting 2008 model is the highest resolution estimate ever created for Australian waste data. Its 343 intermediate sectors, ten treatment sectors and 14 waste types provide a superior understanding of contemporary Australian waste issues when compared to the standard MSW, C\&I and C\&D classification systems found in government reports.

The results section discussed the general situation of waste generation and recycling in Australia, presenting an aggregated seven intermediate sector and ten treatment sector model. We then provided a detailed breakdown of direct and total waste generation multipliers, listing the ten largest of the 343 intermediate sectors for all 14 waste types.

The aggregated analysis affirms the current Australian industry and government understanding of the Australian waste production with the Service (notably construction) industry having the largest direct and total waste generation multipliers. The WSUT also reveals the surprising result of the high indirect waste generation rates found in Agriculture, Manufacturing, Transport, and Mining sectors, illustrating the linkages between these sectors and the rest of the economy. Furthermore the results illustrate the dominant role of construction waste (and the C\&D waste stream) in the 
Australian economy, showing that many sectors contribute indirectly to the construction footprint of Australia. Organic waste-specifically food waste-also features heavily throughout the supply chain. These findings indicate that a change of focus may be required in waste prevention strategy, as currently $C \& D$ waste receives little public attention. The Australian WSUT framework also displays that, per tonne of waste treated, recycling stimulates greater economic activity than landfill. However, landfill operations generate less waste per tonne of waste treated than other waste treatments methods. Though, this volume of waste is small compared to the total amount of waste generated in the economy. This finding should encourage further diversion from landfill.

\section{Competing Interests}

The authors declare that they have no competing interests.

\section{Authors' Contributions}

All authors contributed equally to the writing of this paper. All authors read and approved the final manuscript.

Acknowledgements Many thanks to Shigemi Kagawa, and the two anonymous reviewers for their constructive comments and suggestions. Thanks also to the team at Integrated Sustainability Analysis, University of Sydney for their advice over the writing of this paper. This paper is based on research funded under the ARC Linkage Project 'Zeroing in on Food Waste: Measuring, understanding and reducing food waste' (LP0990554) by the Australian Research Council and industry partners Zero Waste South Australia and the Local Government Association of South Australia.

\section{References}

ACT NOWaste (2008) ACT NOWaste strategy \& targets: review \& assessment of options. Wright Corporate Strategy

Australian Bureau of Statistics (2006) Australian and New Zealand standard industrial classification (ANZSIC) 2006. Australian Bureau of Statistics, Canberra.

Australian Bureau of Statistics (2008) Electricity, gas, water and waste services, Australia. Australian Bureau of Statistics, Canberra

Australian Bureau of Statistics (2009) Environmental issues: waste management and transport use. Australian Bureau of Statistics, Canberra

Australian Bureau of Statistics (2010) Waste generation by state. In: Australia's environment: issues and trends. Australian Bureau of Statistics, Canberra

Australian Bureau of Statistics (2011) Waste management services, Australia, 2009-10. Australian Bureau of Statistics, Canberra

Australian Bureau of Statistics (2013a) Waste account, Australia, experimental estimates (WAAEE) 2013. Australian Bureau of Statistics, Canberra

Australian Bureau of Statistics (2013b) Australian commodities. National and state 2011-12. Australian Bureau of Statistics, Canberra

Department of Environment and Climate Change NSW (2007) NSW waste avoidance and resource recovery strategy 2007

Department of Sustainability, Environment, Water, Population and Communities (2012) Waste and recycling in Australia 2011: incorporating a revised method for compiling waste and recycling data. Final report 
DSEWPaC (2012) The Australian recycling sector. Department of Sustainability, Environment, Water, Population and Communities, Canberra

Environment Division, Department of Environment, Parks, Heritage and the Arts (2009) The Tasmanian waste and resource management strategy

Environment Protection and Heritage Council and the Department of Environment, Water, Heritage and the Arts (2010) National waste report

Hyder Consulting (2012) Waste and recycling in Australia 2011: incorporating a revised method for compiling waste and recycling data. Department of Sustainability, Environment, Water, Population and Communities, Canberra

Kagawa S (2005) Inter-industry analysis, consumption structure, and the household waste production structure. Econ Syst Res 17(4):409-423

Kagawa S, Nakamura S, Inamura H, Yamada M (2007) Measuring spatial repercussion effects of regional waste management. Resour Conserv Recycl 51(1):141-174

Lenzen M, Reynolds C (2014) A supply-use approach to waste input-output analysis. J Ind Ecol $18(2): 212-226$

Lenzen M, Geschke A, Kanemoto K, Moran D (2011) Eora: a global multi-region input-output database. http://www.globalcarbonfootprint.com

Lenzen M, Kanemoto K, Moran D, Geschke A (2012a) Mapping the structure of the world economy. Environ Sci Technol 46(15):8374-8381

Lenzen M, Kanemoto K, Moran D, Geschke A (2012b) Supporting information for "Mapping the structure of the world economy". Environ Sci Technol

Lenzen M, Moran D, Kanemoto K, Geschke A (2013) Building Eora: a global multi-region input-output database at high country and sector resolution. Econ Syst Res 25(1):20-49

Lin C (2009) Hybrid input-output analysis of wastewater treatment and environmental impacts: a case study for the Tokyo Metropolis. Ecol Econ 68(7):2096-2105

Matsubae K, Nakajima K, Nakamura S, Nagasaka T (2011) Impacts on CO2 of the recovery of secondary ferrous materials from alternative ELV treatment methods: a waste input-output analysis. ISIJ Int 51:151-157

Nakamura S (1999) Input-output analysis of waste cycles. In: Proceedings of the EcoDesign '99: first international symposium on environmentally conscious design and inverse manufacturing, 1999

Nakamura S (2010) Waste input-output (WIO) table for Japan 2000, version 0.06b. http://www. f.waseda.jp/nakashin/WIO.html

Nakamura S, Kondo Y (2002a) Input-output analysis of waste management. J Ind Ecol 6(1):39-63

Nakamura S, Kondo Y (2002b) Recycling, landfill consumption, and CO2 emission: analysis by waste input-output model. J Mater Cycles Waste Manag 4(1):2-11

Nakamura S, Kondo Y (2002c) Waste input-output model: concepts, data, and application. KEO discussion paper G-153: inter-disciplinary studies for sustainable development in Asian countries, Keio University

Nakamura S, Kondo Y (2006) A waste input-output life cycle cost analysis of the recycling of end-of-life electrical home appliances. Ecol Econ 57(3):494-506

Nakamura S, Kondo Y (2008) Waste input-output analysis, LCA and LCC. In: Suh S (ed) Handbook on input-output economics in industrial ecology Springer, New York, pp 561-572

Nakamura S, Kondo Y (2009) Waste input-output analysis: concepts and application to industrial ecology. Springer, New York

Nakamura S, Nakajima K, Kondo Y, Nagasaka T (2007) The waste input-output approach to materials flow analysis. J Ind Ecol 11(4):50-63

O’Brien M (1999) Rubbish values: reflections on the political economy of waste. Sci Cult 8(3):269-295

Reynolds CJ (2013) Quantification of Australian food wastage with input-output analysis. Doctor of philosophy (applied mathematics), University of South Australia. http://arrow.unisa.edu.au:8081/ $1959.8 / 157480$

Reynolds CJ, Boland J (2011) Extending the waste input-output model to behavioural change: the case of municipal food waste in South Australia. In: 19th international input-output conference, Alexandria, VA, USA

Reynolds CJ, Boland J (2013a) Waste flows in multi-regional input-output models. In: Murray J, Lenzen M (eds) The sustainability practitioner's guide to multi-regional input-output analysis. Common Ground Publishing LLC, Champaign

Reynolds CJ, Boland J (2013b) Waste not, want not? The economics of waste and the good of charity in a WIO framework. In: 21st IIOA conference, Kitakyushu, Japan 
Reynolds CJ, Boland J, Thompson K, Dawson D (2011) An introduction to the waste input-output model: a methodology to evaluate sustainable behaviour around (food) waste. In: Roetman PE, Daniels CB (eds) Creating sustainable communities in a changing world. Crawford House Publishing, Adelaide

Thompson M (1979) Rubbish theory: the creation and destruction of value. Oxford University Press, Oxford

Tsukui M (2007) Analysis of structure of waste emission in Tokyo by interregional waste input-output table. In: 11th international waste management and landfill symposium, Sardinia

Tsukui M, Nakamura K (2010) The impact and effects of modal shift of waste transportation by IR-WIO (interregional waste input-output) analysis. In: 18th international input-output conference, Sydney, Australia

Tsukui M, Ichikawa T, Kagawa S, Kondo Y, Kagatsume M (2011) A regional WIO analysis of the effect of non-residents' consumption: a comparison between Tokyo and Kyoto. In: 19th international inputoutput conference, Alexandria, VA, USA

Tsukui M, Hasegawa R, Kagawa S, Kondo Y (2012) Construction of a multi-regional waste input-output table. In: 20th international input-output conference, Bratislava, Slovakia

Waste Management \& Environment Media Pty Ltd (2011) Inside waste industry report 2011-12. Gladesville, NSW

WCS Market Intelligence (2008) The blue book: Australian waste industry, 2007/08 industry and market report

Wright Corporate Strategy Pty Ltd and Rawtec Pty Ltd (2010) A study of Australia's current and future ewaste recycling infrastructure capacity and needs. Department of Sustainability, Environment, Water, Population and Communities, Canberra

Zero Waste South Australia (2007) South Australia's waste strategy 2005-2010: benefit cost assessment, volume 1: summary report 